\title{
Vitamin D status in overweight and obese Malaysian school children and its relationship with metabolic syndrome
}

\author{
Nurshadia Samingan ${ }^{1 *}$, Azriyanti Anuar Zaini', Fatimah Harun', Nor Asiah Muhammad², Normi Mustapha ${ }^{3}$, \\ Muhammad Yazid Jalaludin ${ }^{1}$
}

From 8th APPES Biennial Scientific Meeting

Darwin, Australia. 29 October - 1 November 2014

Obesity is a rising health problem, with increasing prevalence in children and adolescents. Lower vitamin D is linked to increased adiposity and higher risk of metabolic syndrome. However, evidence from tropical Asian countries is limited, especially in children and adolescents.

To examine the relationship between vitamin $\mathrm{D}$ level and BMI, abnormal glucose profile, insulin resistance and metabolic syndrome markers in the overweight/ obese secondary school children.

A cross sectional study in multiethnic secondary school children aged 13 -17 years was performed. Anthropometric measurements: height, weight, waist circumference and blood pressure were obtained. Blood for fasting glucose/ lipids/ insulin, and vitamin D $(25(\mathrm{OH}) \mathrm{D})$ were taken. Oral glucose tolerance test was also performed. Insulin resistance indices were calculated based on homeostasis model assessment (HOMA) index.

A total of 543 subjects were enrolled. Forty eight percent were overweight/obese. Most of them (62\%) were vitamin $\mathrm{D}$ deficient $(<50 \mathrm{nmol} / \mathrm{L}), 32 \%$ were vitamin $\mathrm{D}$ insufficient (50 to $<75 \mathrm{nmol} / \mathrm{L}$ ) and only $6 \%$ were vitamin D sufficient ( $\geq 75 \mathrm{nmol} / \mathrm{L})$. Mean $25(\mathrm{OH}) \mathrm{D}$ in the overweight/ obese group was $44.3 \pm 15.9 \mathrm{nmol} / \mathrm{L}$ and was significantly lower compared to the non overweight/ obese group $(47.9 \pm 19.4 \mathrm{nmol} / \mathrm{L}) ;(\mathrm{p}=0.018)$. Females had lower mean vitamin D level $(43.2 \pm 15.9 \mathrm{nmol} / \mathrm{L}) \mathrm{com}$ pared to males $(53.6 \pm 19.6 \mathrm{nmol} / \mathrm{L})(\mathrm{p}<0.001)$. The Chinese had the highest mean vitamin $\mathrm{D}$ level $(65.9 \pm 16.4 \mathrm{nmol} / \mathrm{L})$, followed by Malays $(44.2 \pm 16.9 \mathrm{nmol} / \mathrm{L})$ and Indians $(39.5 \pm 13.3 \mathrm{nmol} / \mathrm{L})(\mathrm{p}<0.001)$.
Among those who were overweight and obese, metabolic syndrome was present in 58 (22\%) of them. No significant relationship was found between 25(OH)D level and abnormal glucose profile, insulin resistance and metabolic syndrome markers among the overweight/obese participants. The overweight/obese females had $78 \%$ prevalence of vitamin D deficiency, compared to $59 \%$ in overweight/obese males. Overweight/obese Indians had the highest prevalence of vitamin D deficiency $(82 \%)$ followed by Malays (70\%) and Chinese (20\%).

Vitamin D deficiency is highly prevalent in Malaysian adolescents despite an abundance of sunlight. Lower vitamin D levels are associated with female gender, ethnic groups with darker skin and obesity. However, no relationship was found between vitamin D deficiency and metabolic syndrome.

\section{Authors' details}

${ }^{1}$ Department of Paediatrics, University Malaya, Kuala Lumpur, Malaysia. ${ }^{2}$ Institute of Medical Research, Kuala Lumpur, Malaysia. ${ }^{3}$ Department of Research Methodology and Biostatics, University Sains Malaysia, Kubang Kerian, Kelantan, Malaysia.

Published: 28 April 2015

doi:10.1186/1687-9856-2015-S1-O50

Cite this article as: Samingan et al:: Vitamin D status in overweight and obese Malaysian school children and its relationship with metabolic syndrome. International Journal of Pediatric Endocrinology 20152015 (Suppl 1):O50. 